\title{
Central Opioid Receptors Differentially Regulate the Nalmefene-Induced Suppression of Ethanol- and Saccharin- Reinforced Behaviors in Alcohol-Preferring (P) Rats
}

\author{
Harry L June*,', Rancia Cummings', William JA Eiler II', Katrina L Foster', Peter F McKay', Regat Seyoum', \\ Marin Garcia', Shannan McCane', Collette Grey', Stephanie E Hawkins' and Dynesha Mason' \\ 'Psychobiology of Addictions Program, Department of Psychology, Indiana University-Purdue University, Indianapolis, IN, USA
}

\begin{abstract}
The exact opioid-sensitive receptors participating in $\mathrm{EtOH}$-seeking behaviors remains unclear. Previous studies have reported higher densities of $\mu$-opioid receptor binding in the nucleus accumbens (NACC) of P relative to NP rats; however, no differences were seen in $\delta$-receptor binding. In contrast to the NACC, substantially lower levels of $\mu$-receptor binding have been observed in the ventral tegmental area (VTA) of both P and NP rats, albeit no line differences have been observed. In the present study, opioid receptors in the NACC, VTA, and hippocampus were evaluated for their capacity to regulate both EtOH- and saccharin-motivated behaviors in the genetically selected alcohol-preferring (P) rat. To accomplish this, nalmefene, an opiate antagonist with preferential binding affinity for the $\mu$-opioid receptor was unilaterally or bilaterally infused during concurrent availability of I h daily EtOH (I0\% v/v) and saccharin ( 0.025 or $0.050 \% \mathrm{w} / \mathrm{v}$ ) solutions. Rats performed under a two-lever fixed ratio (FR) schedule in which four responses on one lever produced the $\mathrm{EtOH}$ solution, and four on a second lever produced the saccharin solution. The results demonstrated that when responding maintained by both $\mathrm{EtOH}$ and saccharin are matched at basal levels, unilateral $(1-60 \mu \mathrm{g})$ or bilateral $(0.5-10 \mu \mathrm{g})$ microinjections of nalmefene into the NACC produced selective dose-dependent reductions on responding maintained by EtOH. Unilateral (40,60 $\mu \mathrm{g})$ and bilateral $(\mathrm{I} 0 \mu \mathrm{g}) \mathrm{VTA}$ infusions were also observed to selectively reduced $\mathrm{EtOH}$ responding; however, greater nalmefene doses were required and the magnitude of suppression on $\mathrm{EtOH}$ responding was markedly less compared with the NACC. The greater sensitivity of nalmefene to suppress $\mathrm{EtOH}$ responding in the NACC is likely due to the greater number of opioid receptors in the NACC relative to the VTA. Only bilateral infusion of the $40 \mu \mathrm{g}$ dose in the NACC and VTA suppressed responding maintained by both EtOH and saccharin. In contrast, intrahippocampal infusions dose dependently suppressed $\mathrm{EtOH}$ - and saccharin-maintained responding over a range of doses $(\mathrm{I}-20 \mu \mathrm{g})$. The present study provides evidence that nalmefene suppresses EtOH-motivated behaviors via blockade of opioid receptors within the NACC and VTA, and under various dose conditions both reinforcer and neuroanatomical specificity can be observed.
\end{abstract}

Neuropsychopharmacology (2004) 29, 285-299, advance online publication, 5 November 2003; doi: I0.1038/sj.npp. 1300338

Keywords: alcohol-preferring $(P)$ rats; ethanol-motivated behaviors; alcohol reinforcement; nucleus accumbens; ventral tegmental area; mesolimbic; opioid receptors

\section{INTRODUCTION}

The endogenous opioid systems provide the brain with mechanisms that regulate not only opioid addiction, but the addiction of a variety of abused drugs. Unraveling the mechanisms of the endogenous opioid systems have provided valuable insight into many of these addictive behaviors, particularly in relation to alcohol dependence (Herz, 1997). While a variety of neuronal systems have been

\footnotetext{
*Correspondence: HL June, Department of Psychology, LD I24, IUPUI, 402 North Blackford Street, Indianapolis, IN 46202-3275, USA, Tel: + I 317274 6755, Fax: + I 317274 6756, E-mail: hjune@iupui.edu Received 24 September 2002; revised 02 September 2003; accepted 15 September 2003

Online publication: 25 September 2003 at http://www.acnp.org/ citations/Npp0925030235 I/default.pdf
}

shown to play a role in regulating EtOH-seeking behavior (McBride and Li, 1998; McBride et al, 1993) few have been linked as closely to the positive reinforcing properties of EtOH as the endogenous opioid systems (for a review, see Froehlich and Li, 1993; Herz, 1997; Reid and Hubbell, 1992). This conclusion is supported by pharmacological studies showing that selective (eg $\delta$ and $\mu$ ) and nonselective (eg naloxone, naltrexone, nalmefene) opioid antagonists can decrease EtOH-seeking behaviors in a variety of preclinical animals models, suggesting that the endogenous opioid systems mediate in part, EtOH-reward processes (Herz, 1997; June et al, 1999; June et al, 1998; Krishnan-Sarin et al, 1995a). Similarly, it is also well established that the nonselective opioid antagonists naltrexone and nalmefene attenuate alcohol drinking behavior, control craving, and prevent relapse in alcohol-dependent humans (O’Malley 
et al, 1992; Volpicelli et al, 1992; Mason et al, 1994, 1999) albeit, the effectiveness of these agents has been limited by problems with compliance (Volpicelli et al, 1997; Johnson and Ait-Daoud, 2000; Kranzler, 2000).

The exact neurobiological substrate(s) participating in EtOH's rewarding effects, however, are not well understood, in part because the majority of the preclinical studies using opioid antagonists have been conducted using systemic drug injections (Froehlich and Li, 1993; Herz, 1997; Reid and Hubbell, 1992; Schwartz-Stevens et al, 1992). While it has been assumed that the action of opioid antagonists on EtOH's reinforcing properties are mediated centrally (McBride and Li, 1998), this has only been documented in a few published reports in the literature (Heyser et al, 1999; Hyytiä and Kiianmaa, 1997).

Previously, Heyser et al (1999) showed that local injection of methylnaloxonium into the nucleus accumbens (NACC) and amygdala blocked EtOH self-administration in outbred Wistar rats. An earlier study by Hyytiä and Kiianmaa (1997) evaluated the capacity of the $\mu$-selective antagonist, CTOP, and the $\delta_{1}$-receptor antagonist, naltrindole to reduce EtOHmaintained responding when infused into the NACC, basolateral amygdaloid nucleus (BLA), and ventral tegmental area (VTA) in Wistar rats. Their results showed that CTOP suppressed EtOH responding only when injected in the BLA, while naltrindole suppressed EtOH responding following infusion into both the NACC and BLA. In contrast, both agents were ineffective when infused into the VTA. These results suggest that both $\mu$ - and $\delta$-opioid recptors may differentially regulate $\mathrm{EtOH}$-maintained responding in the NACC and BLA, but that opioid receptors within the VTA do not appear salient in regulating responding maintained by EtOH.

While a voluminous literature support a role for nonselective and selective opioid antagonists as potential pharmacotherapies in humans, a selective role for opioid mechanisms in alcohol reward is still a matter of debate (Brown and Holtzman, 1979; Herz, 1997; Reid and Hubbell, 1992; Schwartz-Stevens et al, 1992; Weiss and Koob, 1991; Weiss et al, 1990). Some researchers have argued that while both EtOH and other palatable reinforcers are affected by opioid antagonists, the relative magnitude of suppression is far less for water, sucrose, and saccharin solutions (see June et al, 1998, 1999; Heyser et al, 1999). Still others contend that because the endogenous opioid systems mediate natural reinforcers (ie hunger, thirst, sex, etc) it is not realistic to expect a complete separation between EtOH intake and intake of other palatable reinforcers (Herz, 1997).

Unfortunately, little if any research has systematically investigated the effects of opioid antagonists on the concurrent availability of $\mathrm{EtOH}$ and an alternative reinforcer in rodents, and no studies could be found that have examined the action of opioid antagonists following direct microinjection into putative $\mathrm{EtOH}$ reinforcing areas in such paradigms. The importance of alternative and concurrently available reinforcers in EtOH-maintained responding paradigms has been previously (Carroll et al, 1991; Heyman and Oldfather, 1992; Petry and Heyman, 1995; Rodefer et al, 1999; Samson and Grant, 1985) and recently (June, 2002) addressed. In addition, no studies could be found in the literature that have used neuroanatomical control groups to evaluate site-specific effects on EtOH-motivated behaviors, or motivated behaviors initiated by a palatable alternative solution. Thus, the degree to which selective and nonselective opioid antagonists reduce EtOH-maintained responding/drinking is not clear. Recently, June (2002) has discussed the relative importance of using neuroanatomical control groups in microinjection studies when researchers are trying to isolate brain substrates, which regulate EtOHmotivated behaviors.

The objective of the present study was to determine the role of central opioid receptors in EtOH-motivated behaviors in the alcohol-preferring $(\mathrm{P})$ rat. To accomplish this, nalmefene, a high affinity $\left(\mathrm{IC}_{50} \sim 1 \mathrm{nM}\right)$ (Michel et al, 1985) nonselective opioid antagonist was evaluated following unilateral and bilateral microinjection into the NACC and VTA. The unilateral infusions were performed to determine the minimal level of opioid receptor occupancy required to observe modulation of EtOH- or saccharin-motivated behaviors. The degree of neuroanatomical specificity produced by nalmefene was examined following bilateral injections into the CA1 and CA3 hippocampal areas. The hippocampal fields contain substantial levels of $\mu$ - and $\delta$ opioid receptors (Mansour et al, 1987, 1995; McBride and $\mathrm{Li}, 1998$ ); however, the opioid receptors in the hippocampus have not been reported to play a role in alcohol reinforcement. The selectivity of nalmefeme on consummatory responding was evaluated by determining nalmefene's effects in $\mathrm{P}$ rats whose response rates for EtOH $(10 \% \mathrm{v} / \mathrm{v})$ and saccharin solutions $(0.05 \% \mathrm{w} / \mathrm{v})$ were matched at basal levels.

\section{EXPERIMENTAL PROCEDURES}

\section{Animals}

Female, selectively bred $\mathrm{P}$ rats $(N=56)$ from the $\mathrm{S} 47$ and S48 generations (Lumeng et al, 1995) were approximately 34 months of age at the beginning of the experiment. No effects of estrous cycle have been observed on $\mathrm{EtOH}$ drinking patterns in female $\mathrm{P}$ rats (McKinzie et al, 1996), and female rats maintain their body weights within a range that allows for more accurate stereotaxic placement than male P rats (Nowak et al, 1998). During the initial phase of the study, the rats weighed between 204 and $346 \mathrm{~g}$. Animals were individually housed in wire-mesh stainless-steel cages or plastic tubs. The vivarium was maintained at an ambient temperature of $21^{\circ} \mathrm{C}$ and was on a normal $12 \mathrm{~h}$ light cycle (lights on at 0700). All rats were provided ad libitum access to food and water, except during the first 2 days of the training phase wherein rats were fluid deprived $23 \mathrm{~h}$ daily (see below). Thereafter, rats were maintained on ad libitum food and water. All training and experimental sessions took place between 0900 and 1500 . All procedures were conducted in strict adherence with the NIH Guide for the Care and Use of Laboratory Animals.

\section{Drugs and Solutions}

$\mathrm{EtOH}(10 \% \mathrm{v} / \mathrm{v})$ and saccharin solutions $(0.05 \% \mathrm{~g} / \mathrm{v})$ were prepared for the operant chamber as previously described (June et al, 1998, 1999). Nalmefene, [17-N-cyclopropylmethyl-3,14b-dihydroxy-4,5a-epoxy-6-methylene-morphinan 
hydrochloride], the 6-methylene derivative of naltrexone was donated as a gift by IVAX Pharmaceuticals (Miami, FL).

\section{Behavioral Testing Apparatus}

Behavioral testing was conducted in 15 standard operant chambers (Coulbourn Instruments) equipped with two removable levers and two dipper fluid delivery systems enclosed in sound-attenuated cubicles. All dipper presentations provided a 1.5-s access to a 0.1-ml dipper, followed by a 3-s time out period. Above each lever, three stimulus lights (red, green, and yellow) were present, and a stimulus delivery/reinforcer was indicated by illumination of the middle (green) stimulus light. Responses were recorded and reinforcements were controlled by two Dell computers using the 4.0 Coulburn L2T2 operant software package.

\section{Behavioral Training and Testing Procedures}

Rats were trained to orally self-administer EtOH in daily $60 \mathrm{~min}$ sessions using previously described procedures (June et al, 1998, 1999; June, 2002). Briefly, rats were initially placed on a $23 \mathrm{~h}$ fluid restriction schedule for the first 2 days of training. During this period, they were trained to respond to a $0.1 \%(\mathrm{w} / \mathrm{v})$ saccharin solution on a continuous reinforcement schedule (ie fixed ratio (FR1) schedule). On day 3, following successful acquisition of responding, water was available ad libitum for the remainder of the experiment. On the fourth day of the training phase, EtOH $(5 \% \mathrm{v} / \mathrm{v})$ was added to the $0.1 \%(\mathrm{w} / \mathrm{v})$ saccharin solution, and over the next 5 days, EtOH was gradually increased stepwise to $10 \%(\mathrm{v} / \mathrm{v})$ (ie $5,7,9,10$, $10 \%)$, while saccharin decreased $(0.1,0.075,0.05,0.0125$, $0.0 \%)$. After a period of stabilization on the concurrent FR1 schedule for $\mathrm{EtOH}$ and water, the response requirement was increased to a concurrent FR4 schedule. Following stabilization on the concurrent FR4 schedule, a series of preliminary studies were conducted to determine the saccharin concentration that produced response rates similar to that of EtOH (see June et al, 1998, 1999; June, 2002). Of the saccharin concentrations tested, the 0.025 and $0.05 \% \mathrm{w} / \mathrm{v}$ concentrations produced rates of responding that were similar to EtOH in the rats tested. Stabilization on the concurrent FR4 schedule for EtOH and the saccharin concentration $(0.05$ or $0.025 \% \mathrm{w} / \mathrm{v})$ was conducted for 3 additional weeks prior to beginning the drug treatment phase. Responding was considered stable when responses were within $+20 \%$ of the average responses for 5 consecutive days. The position of the levers and associated dippers for each reinforcer was alternated on each session to avoid the establishment of lever preference under all concurrent schedules.

\section{Rationale for Selection of Brain Sites}

The NACC, VTA, and hippocampus (CA1 and CA3 fields) were the brain sites selected to evaluate the actions of nalmefene on EtOH-maintained responding. The NACC was selected as the primary brain substrate of interest since the majority of the previous literature has implicated the NACC as a substrate in which several types of opioid receptors regulate alcohol drinking behavior (Koob et al, 1998; McBride and $\mathrm{Li}, 1998)$. It was also selected as the primary substrate since moderate-high densities of different types of opioid receptors have been reported in the NACC (Mansour et al, 1987; McBride and Li, 1998; McBride et al, 1998a). The VTA was selected as the second substrate since it has been consistently reported that differences in endogenous opioids and opioid receptors in this locus might contribute to alcohol preference in some alcohol-selected rodent lines (for a review, see McBride and $\mathrm{Li}$, 1998). However, opioidreceptor density within the VTA has been reported to be very low (Mansour et al, 1987; McBride et al, 1998a). Further, previous research has shown that opioid receptors in the VTA play a minor role in regulating EtOHmaintained responding (Hyytiä and Kiianmaa, 1997) or intake of a palatable sucrose solution (Ragnauth et al, 1997). Thus, equivocal reports appear to exist on the significance of the VTA in alcohol self-administration. The hipppocampus was selected as the control locus since it is one of the few mesolimbic substrates that contains a significantly lower density of $\mu$-opioid receptors in the $\mathrm{P}$ compared with the NP rats (McBride et al, 1998a). In addition, to our knowledge, opioid receptors within the hippocampus have not been reported to regulate alcohol-motivated behaviors. Hence, the negative association between hippocampal $\mu$ opioid receptors and alcohol preference make the hippocampus an ideal neuroanatomical control locus for reinforcement studies.

\section{Assignment to Surgical Groups}

Despite extensive training, only a subpopulation of rats were capable of lever pressing concurrently for $\mathrm{EtOH}(10 \%$ $\mathrm{v} / \mathrm{v}$ ) and a saccharin reinforcer at relatively similar rates of responding. Hence, only rats that evidence response rates of approximately $70 \%$ or greater of the alternative reinforcer were selected to evaluate the drug treatments. Using this criterion, 63 rats were selected to participate in the study. Of these, 32 rats lever pressed for $10 \%$ (v/v) EtOH and $0.025 \%$ $(\mathrm{w} / \mathrm{v})$ saccharin at similar rates, while the remaining 31 lever pressed for $10 \%(\mathrm{v} / \mathrm{v}) \mathrm{EtOH}$ and $0.05 \%(\mathrm{w} / \mathrm{v})$ saccharin at similar rates. For the specific details on how rats are trained to lever press for two reinforcers at relatively similar rates see June (2002). Out of the 32 rats, 15 were then randomly assigned to the bilateral VTA group, and 15 to the bilateral NACC group. Of the remaining 31 rats, 10 were randomly assigned to the bilateral CA1 and CA3 hippocampal control group, while nine were randomly assigned to the unilateral VTA group and nine to the unilateral NACC group.

\section{Implantation of Guide Cannulae}

Guide cannulas were stereotaxically implanted unilaterally and bilaterally in the VTA (AP -5.3/6.3; ML + 1.6; DV -9.2) and NACC (AP +2.0/1.70; ML + 1.8; DV -7.2). Animals were implanted in the anterior $(50 \%)$ to medial (50\%) NACC and the anterior $(50 \%)$ to posterior $(50 \%)$ VTA since these areas have been shown to be associated with both natural and drug-related rewards (Kelley and Berridge, 2002; Rodd-Henricks et al, 2000; Nowak et al, 1998). The anterior VTA was defined as the VTA region at the level of the mammillary nuclei (Bregma -4.8 to 
$-5.6 \mathrm{~mm})$. The posterior VTA is defined as the VTA region at the levels of the caudal linear (CLi) (Bregma -5.80 to -6.04 ), interpeduncular (Bregma -6.04 to -6.30 ), and pontine (Bregma -6.72 to -6.80 ) nuclei (see Ikemoto et al, 1997; Rodd-Henricks et al, 2000). Only bilateral hippocampal implants were performed in the CA1 and CA3 areas (AP -4.8; $\mathrm{ML}+3.0 ; \mathrm{DV}-3.8)$. In experimental and control animals, the cannulas were aimed $1 \mathrm{~mm}$ above the intended brain locus. Stereotaxic coordinates were established according to the Paxinos and Watson atlas (1986). Rats were allowed to recover for 7 days before returning to training in the operant chamber.

\section{Microinjection Procedures}

When nalmefene was microinjected into a brain site it was dissolved in artificial cerebrospinal fluid (aCSF) (composition in $\mathrm{mM}$ : $\mathrm{NaCl}, 120 ; \mathrm{KCl}, 4.8 ; \mathrm{KH}_{2} \mathrm{PO}_{4}, 1.2 ; \mathrm{MgSO}_{4}, 1.2$; $\mathrm{NaHCO}_{3}, 25 ; \mathrm{CaCl}_{2}, 2.5$; D-glucose, 10). When necessary, $\mathrm{HCl}$ acid or $\mathrm{NaOH}$ was added to the solutions to adjust $\mathrm{pH}$ levels to $\sim 7.4 \pm 0.1$. Nalmefene or aCSF was infused bilaterally for $5 \mathrm{~min}$ at a rate of $0.1 \mu \mathrm{l} / 1 \mathrm{~min}$ using a 28 gauge injector cannula. The injector cannula was connected by polyethyene tubing to a $10 \mu \mathrm{l}$ Hamilton microsyringe. The injection volume delivered to each hemisphere was $0.5 \mu \mathrm{l}$, while the total injection volume for both the left and right hemispheres was $1 \mu$ l. Thus, if a rat received a drug treatment of $20 \mu \mathrm{g}$, both the left and right hemispheres received $10 \mu \mathrm{g}$ in a volume of $0.5 \mu \mathrm{l}$. Rats receiving unilateral infusions received their drug dose in a total injection volume of $1 \mu \mathrm{l}$. The injections were delivered immediately before the operant session with a Harvard infusion pump (model A), during which time animals were able to move about freely in their home cages. The injection cannula extended $1 \mathrm{~mm}$ beyond the tip of the guide cannulae. After completion of the $5 \mathrm{~min}$ infusion period, the injector was left in place for an additional 1 min to allow diffusion from the needle tip.

\section{Rationale for Selection of Doses in the NACC and VTA}

The dose range of nalmefene was selected based on previous research in our laboratory evaluating the actions of unilateral and bilateral infusions in selected brain loci (Cummings et al, 1999). In these studies, we attempted to determine the minimal level of opioid receptor occupancy required to observe modulation of EtOH- or saccharinmotivated behaviors in a single hemisphere. Preliminary results suggested that the minimal effective dose (MED), which selectively suppressed EtOH-maintained responding following unilateral infusion in the NACC was $10 \mu \mathrm{g}$, while the MED in the VTA was $20 \mu \mathrm{g}$. The MED dose that selectively suppressed EtOH-maintained responding following bilateral infusions, in the NACC was $0.25 \mu \mathrm{g}(0.125 \mu \mathrm{g} /$ per hemisphere), while the MED in the VTA was $7.5 \mu \mathrm{g}$. As expected, occupancy of more opioid receptors with bilateral infusions was substantially more effective than unilateral infusions in suppressing EtOH responding; hence, greater doses were required to observe comparable suppression with unilateral infusions. Thus, the highest nalmefene dose employed in the unilateral studies was $60 \mu \mathrm{g}$, while the highest dose in the bilateral studies was $40 \mu \mathrm{g}$. To control for carryover effects in the present study, subsequent pretreatments were not administered until both EtOHand saccharin-maintained responding had returned to their predrug baseline levels for at least 3 days, with a minimum of 3 days between all drug treatments and a maximum of 4 days.

\section{Histology}

After the completion of the behavioral testing, animals were killed by $\mathrm{CO}_{2}$ inhalation. Cresyl violet $(0.5 \mu \mathrm{l})$ was injected into the infusion site, and the brain was removed and frozen. The frozen brains were sliced on a microtome at $50 \mu \mathrm{m}$ sections and the sections were stained with cresyl violet acetate. Infusions sites were examined under a light microscope and indicated on drawings adapted from the rat brain atlas of Paxinos and Watson (1986). Rats with improper placements were excluded from the final data analysis.

\section{Blood Alcohol Concentration (BAC) Measurement}

To ensure animals were consuming pharmacologically relevant amounts of EtOH during operant sessions, BACs were collected in a subset of animals on days animals did not receive drug treatment. After the first $20 \mathrm{~min}$ of an operant session, approximately $100 \mu \mathrm{l}$ of whole blood was collected from the rats tail tip into a heparin-coated microsample tube. The BAC samples were collected at the 20 min time point since the majority of EtOH-maintained responding typically occurs during the first half of the operant session (June et al, 1998, 1999; June, 2002). In addition, an attempt was made to determine the rising phase of the BAC since it has been demonstrated that the rising, but not the falling phase of the blood alcohol curve correlated significantly with the euphoric properties of EtOH (Lewis and June, 1990). After collection, the whole blood was immediately centrifuged for $5 \mathrm{~min}$ at $1100 \mathrm{rpm}$. Plasma samples of $5 \mu \mathrm{l}$ were collected with a Gilson Microman M-25 Pipette and injected directly into a GL-5 Analyzer (Analox Instruments; Luxenburg, MA). Microanalysis consisted of measuring the oxygen consumption in the reaction between the sample of alcohol and alcohol oxidase (AOD) using a Clark-type amperometric oxygen electrode. Alcohol reagent buffer solutions $(\mathrm{pH} 7.4)$ and alcohol oxidase enzymes were used in all samples tested. Results were calculated in units of $\mathrm{mg} / \mathrm{dl}$ and printed within $20 \mathrm{~s}$ of each trial. To assure accuracy of measurement, each BAC sample was calibrated twice. The mean of the two samples was used as an index of the level of BAC content for a given rat. Single point calibrations were carried out using $5 \mu \mathrm{l}$ of aqueous $100 \mathrm{mg} / \mathrm{dl}(21.7 \mathrm{mmol} / \mathrm{l})$ standard.

\section{Statistical Analysis}

The operant-maintained responding data were analyzed by a single factor repeated measures ANOVA with drug treatment (ie dose) as the independent factor. All microinjection data were analyzed following correct histological verification under light microscope. The dependent variables were EtOH- and saccharin-maintained responding. Each dependent variable was analyzed separately. Post hoc 
comparisons between individual drug treatments were made using the Newman-Keuls test in all experiments. In general, drug treatment comparisons were made against the aCSF control condition and the no injection baselines (ie BL1, BL2). The BL1 condition was the average of 5 days before the animals received any drug treatment, while the BL2 condition was the average of 5 days after animals received their final drug treatment. The first day of the BL2 condition was taken 3 days after the rats final drug treatment. The BL1 and BL2 conditions were included in the design to evaluate the reliability of our operant training procedures across the entire duration of the study, and to serve as an additional control condition to compare our aCSF control treatment (see June et al, 2001; June, 2002). None of the baseline conditions were statistically significant from each other $(p>0.05)$. As a result, the BL1 and BL2 conditions were pooled into a single 'BL condition' in the bilateral NACC and VTA groups (Figures $1 \mathrm{c}$ and d). The BL conditions were not included in the unilateral studies due to the rather brief time course of the studies. By assessing the BL data, it was possible to determine any baseline shifting over the longer time periods within the bilateral studies. Correlated t-test was used to determine if the EtOH- and saccharin-maintained responding data were equivalent within the NACC, VTA, and hippocampal groups. For all cumulative time course analyses, data were evaluated using a two-way ANOVA with repeated measures over both time interval and dose.

\section{RESULTS}

\section{Control Rates of EtOH- and Saccharin-Maintained Responding and BACs for Unilateral Rats}

Under control conditions EtOH- and saccharin-maintained responding were similar in the NACC $(p>0.05)$ and VTA $(p>0.05)$ groups. Responding for the $\mathrm{EtOH}$ and saccharin reinforcers in the NACC group $(N=5)$ following the aCSF infusion was $148 \pm 34$ and $188 \pm 39$, respectively (see Figure 1a). Responding for the EtOH and saccharin reinforcers in the VTA group $(N=5)$ following the aCSF infusion was $146 \pm 35$ and $192 \pm 45$, respectively (see Figure 1b). For the two groups of rats, responding maintained by EtOH on the day of blood $\mathrm{EtOH}$ analysis ranged from 108 to 289 responses/30 min, while BACs ranged from 24 to $86 \mathrm{mg} / \mathrm{dl}$. Intake of absolute $\mathrm{EtOH}$ ranged from 0.67 to $2.49 \mathrm{~g} / \mathrm{kg}$. In the NACC rats $(n=5)$, a significant correlation emerged between EtOH-maintained responding $(r=0.68, p<0.05)$ and intake $(r=0.78$, $p<0.05)$. The BACs in the VTA rats $(n=5)$ were also correlated with EtOH-maintained responding and intake $(r=0.72, p<0.05, r=0.82, p<0.05$, respectively).

\section{Control Rates of EtOH- and Saccharin-Maintained Responding and BACs for Bilateral Rats}

Under control conditions EtOH- and saccharin-maintained responding were similar in the bilateral NACC $(p>0.05)$ and VTA $(p>0.05)$ groups. Following the aCSF infusions, rats in the bilateral NACC group $(N=9)$ averaged $161 \pm 31$ responses for $\mathrm{EtOH}$ and $123 \pm 19$ responses for saccharin (see Figure 1c). Responding under baseline

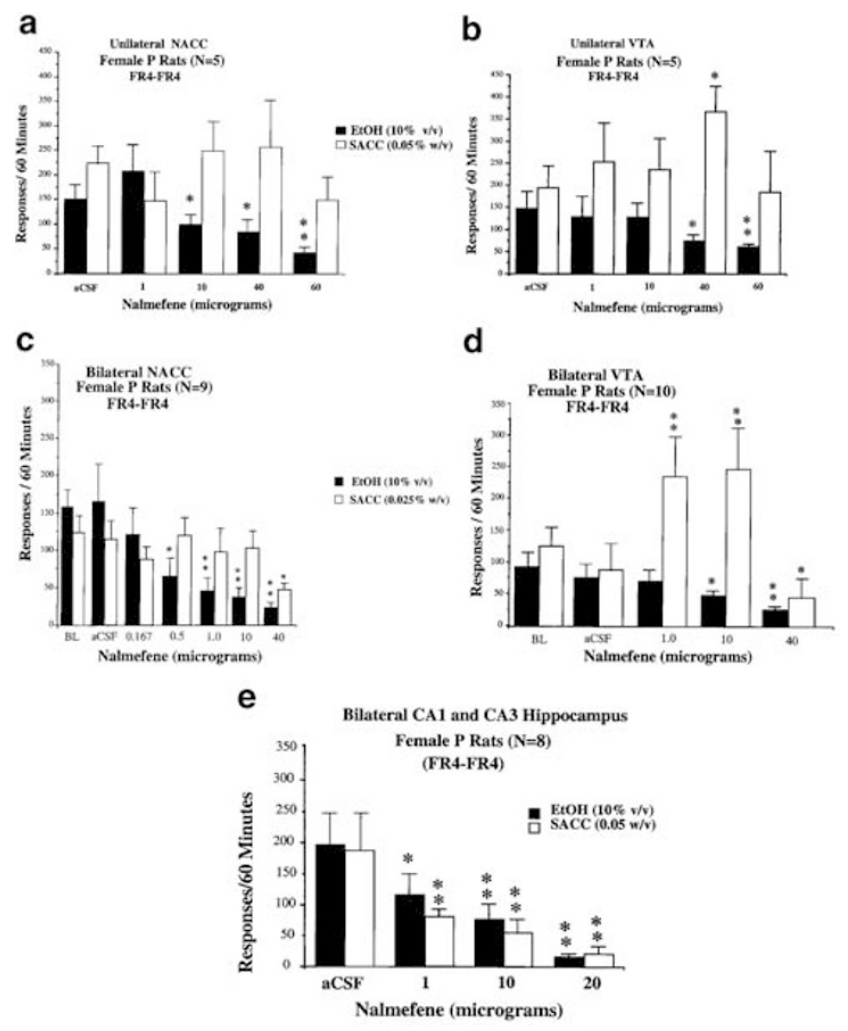

Figure I Effects of nalmefene $(I-60 \mu \mathrm{g})$ following unilateral or bilateral microinjection in the NACC (core or shell) (a, c), VTA (anterior or posterior) (b, d), or CAI and CA3 hippocampal fields (e) on responding maintained by $\mathrm{EtOH}(\mathrm{I} \% \% \mathrm{v} / \mathrm{v})$ (black bar) and saccharin $(0.025$ or $0.05 \%$ w/v) (white bar) during a I h operant session. Data are shown as mean ( \pm SEM), $* P<0.05$, *** $P<0.01$, namefene vs aCSF/baseline (BL) conditions $(N=5$ for unilateral NACC and VTA groups; $N=9$ and 10 for bilateral NACC and VTA groups, respectively; $N=8$ for bilateral CAI and CA3 hippocampal groups)

conditions were similar. The bilateral NACC group consumed $5.2 \pm 1.1 \mathrm{ml}$ of pure EtOH and their BACs ranged from 21.6 to $94.3 \mathrm{mg} / \mathrm{dl}$. Following the aCSF infusions, rats in the bilateral VTA group $(N=10)$ averaged $93.71 \pm 21$ responses for EtOH and $85 \pm 27$ responses for saccharin (see Figure 1d). Responding under the baseline condition was not statistically different from the aCSF condition $(p>0.05)$. The bilateral VTA group consumed $3.91 \pm 1.2 \mathrm{ml}$ of pure EtOH and their BACs ranged from 29.7 to $104.22 \mathrm{mg} / \mathrm{dl}$. Rats in the bilateral hippocampal group $(N=8)$ averaged $192 \pm 38$ response for $\mathrm{EtOH}$ and $183 \pm 45$ responses for saccharin (see Figure 1e). The bilateral hippocampal group consumed $5.4 \pm 1.4 \mathrm{ml}$ of pure EtOH and their BACs ranged from 20.6 to $94.22 \mathrm{mg} / \mathrm{dl}$. Intake of absolute EtOH ranged from 0.86 to $3.69 \mathrm{~g} / \mathrm{kg}$. In the NACC rats $(n=7)$ BACs correlated with EtOH-maintained responding and intake $(r=0.78, p<0.05$ and $r=0.71, p<0.05$, respectively). The BACs in the VTA rats $(n=6)$ were also highly correlated with EtOH-maintained responding and intake $(r=0.81, p<0.01$, and $r=0.77$, $p<0.01$, respectively). In addition, the BACs (ie $\mathrm{mg} / \mathrm{dl}$ ) in the hippocampus rats $(n=6)$ correlated significantly with EtOH-maintained responding and intake $(r=0.79, p<0.01$ and $r=0.72, p<0.01$, respectively. 


\section{Experiment 1 (NACC) Unilateral Study}

Histology. Figure 4a illustrates the histologies for the five animals with correct unilateral placements in the NACC (solid circles). Of the correctly placed rats, three had their cannulae in the anterior NACC (Bregma: 2.70, 2.20), while the two remaining rats had more medial to posterior placements (Bregma: 1.70, 1.20). Representative unilateral photomicrographs (Figures $5 \mathrm{~d}$ and e) are depicted with the bilateral photomicrographs.

Microinfusions. Figure 1a (black bar) shows rates of responding maintained by EtOH following unilateral microinjection of the 1-60 $\mu \mathrm{g}$ doses of nalmefene into the NACC core or shell. Compared with the aCSF control condition responding was reduced with the 10-60 $\mu \mathrm{g}$ doses by $44-83 \%$ of control levels resulting in a highly significant main effect of drug treatment $(F(4,16)=12.13, p<0.0001)$. In contrast, unilateral nalmefene produced little effects on saccharin-maintained responding $(\mathrm{F}(4,16)=0.576$, $p>0.05$ ) (Figure 1a, white bar). The Newman-Keuls post hoc test confirmed that the $10-60 \mu \mathrm{g}$ doses significantly reduced EtOH-maintained responding $(p<0.05)$; however, no effects were seen on saccharin-maintained responding $(p>0.05)$.

Cumulative time course. As noted above, all cumulative time course data were evaluated using a two-way ANOVA with repeated measures over both time interval and dose. The cumulative $6 \times 5$ analyses were as follows for $\mathrm{EtOH}$ : interval $(\mathrm{F}(5,24)=32.03, p<0.0001)$; dose $(\mathrm{F}(4,96)=77.34$, $p<0.0001)$; interaction $(\mathrm{F}(20,96)=18.46, p<0.0001)$. The cumulative $6 \times 5$ analyses for saccharin were: interval $(\mathrm{F}(5,24)=16.08, \quad p<0.0001) ; \quad$ dose,$\quad(\mathrm{F}(4,96)=34.22$, $p<0.0001)$; interaction $(\mathrm{F}(20,96)=20.45, p<0.0001)$. Post hoc analyses using the Newman-Keuls test were conducted against the aCSF control condition. Figure 2a shows that nalmefene failed to suppress EtOH-maintained responding at the $10 \mathrm{~min}$ interval with any tested dose $(p>0.05)$. However, at the $20-50 \mathrm{~min}$ intervals nalmefene suppressed EtOH-maintained responding with the 10-60 $\mu \mathrm{g}$ doses $(p<0.05)$, albeit suppression with the $10 \mu \mathrm{g}$ dose dissipated by the $60 \mathrm{~min}$ interval $(p>0.05)$. The 40 and $60 \mu \mathrm{g}$ doses continued to suppress responding at the $60 \mathrm{~min}$ interval $(p<0.05)$. Similar to alcohol-maintained responding, Figure $2 \mathrm{~b}$ shows that saccharin-maintained responding was not significantly altered at the initial 10 min interval relative to the control condition $(p>0.05)$. In contrast, to alcohol responding, however, the $40 \mu \mathrm{g}$ dose significantly elevated saccharin responding from the 20 to $50 \mathrm{~min}$ interval $(p<0.05)$. The $10 \mu \mathrm{g}$ dose did not significantly alter saccharin-maintained responding at any interval $(p>0.05)$ (Figure $2 \mathrm{~b}$ ). At the 30-60 min intervals the 1 and $60 \mu \mathrm{g}$ doses suppressed responding $(p<0.05)$, but neither significantly altered responding during the $20 \mathrm{~min}$ interval $(p>0.05)$.

\section{Experiment 2 (Unilateral VTA Study)}

Histology. Figure 4c shows the histological placements for the five animals with correct unilateral placements in the VTA. Of the correctly placed rats, three had their cannulae in the anterior VTA at the level of the mammillary nuclei
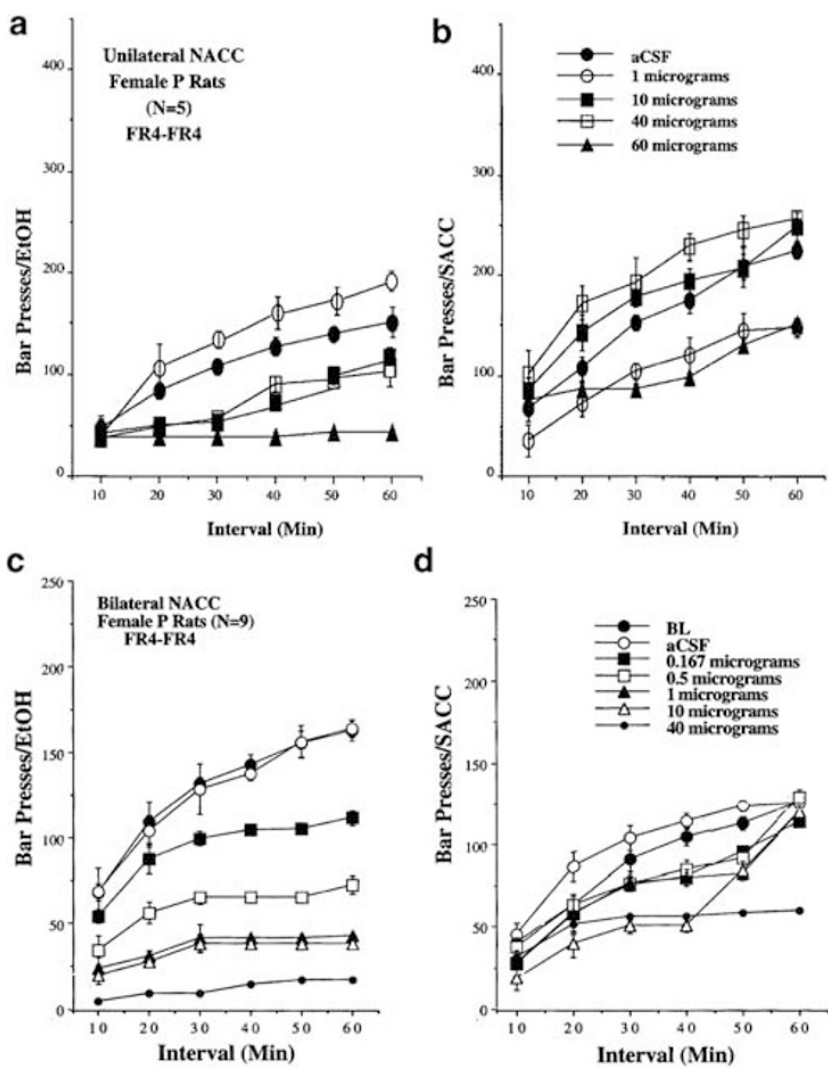

Figure 2 Cumulative time course profiles following unilateral or bilateral microinjection of nalmefene $(\mathrm{I}-60 \mu \mathrm{g})$ in the NACC across the $60 \mathrm{~min}$ interval for $\mathrm{EtOH}(\mathrm{a}, \mathrm{c})$ and saccharin-maintained responding (b, d) relative to the aCSF condition. The data are redrawn from Figure la and $c$. Nalmefene was without effects on $\mathrm{EtOH}$ responding during the intial 10 min interval following the unilateral infusions; however, the 10-60 $\mu \mathrm{g}$ doses suppressed $\mathrm{EtOH}$ responding by the 20 min interval $(P<0.05)(a)$, see Results section. In contrast to the unilateral infusions, bilaterally microinjected nalmefene into the NACC produced a clear dosedependent (eg $0.167-40 \mu \mathrm{g}$ ) suppression on responding maintained by $\mathrm{EtOH}$ during the initial 10 min interval $(p \leqslant 0.05)$ (c). Saccharin-maintained responding was not significantly altered at the initial 10 min interval relative to the control condition with either unilateral (b) or bilateral (d) injections $(p>0.05)$.

(Bregma: $-5.20,-5.30,-5.60$ ), while the two remaining rats had more posterior placements at the levels of the interpenducular (IP) and CLi nuclei (Bregma -6.04, $-6.30)$. A representative unilateral photomicrograph is depicted (Figure 6c) with the bilateral histologies.

Microinfusions. Figure $1 \mathrm{~b}$ (black bar) shows rates of responding maintained by $\mathrm{EtOH}$ following unilateral microinjection of the 1-60 $\mu \mathrm{g}$ doses of nalmefene into the anterior or posterior VTA. Compared with the aCSF control condition, responding was reduced only with the 40 and $60 \mu \mathrm{g}$ doses. Maximal suppression was approximately $66 \%$ of control levels with the $60 \mu \mathrm{g}$ dose. Both doses, however, resulted in a significant main effect of drug treatment $(\mathrm{F}(4,16)=3.03, p<0.05)$. Unilateral nalmefene produced elevations in saccharin-maintained responding with the $40 \mu \mathrm{g}$ dose (Figure $1 \mathrm{~b}$, white bar), however, the overall ANOVA only approached significance $(\mathrm{F}(4,16)=2.34$, $p>0.10)$. Post hoc test confirmed that the 40 and $60 \mu \mathrm{g}$ doses significantly reduced EtOH-maintained responding 
( $p<0.05)$, while the $40 \mu$ g dose elevated responding maintained by saccharin $(p<0.05)$.

Cumulative response profile. The cumulative $6 \times 5$ analyses were as follows for EtOH: interval $(\mathrm{F}(5,24)=19.45$, $p<0.0001)$; dose $(\mathrm{F}(4,96)=8.56, p<0.0001)$; interaction $(\mathrm{F}(20,96)=12.79, p<0.0001)$. Nalmefene failed to alter alcohol-maintained responding at the initial $10 \mathrm{~min}$ interval $(p>0.05)$ (Figure 3a). However, nalmefene suppressed EtOH-maintained responding at the $30 \mathrm{~min}$ interval with the 10 and $60 \mu \mathrm{g}$ doses $(p<0.05)$. With the $40 \mu \mathrm{g}$ dose the
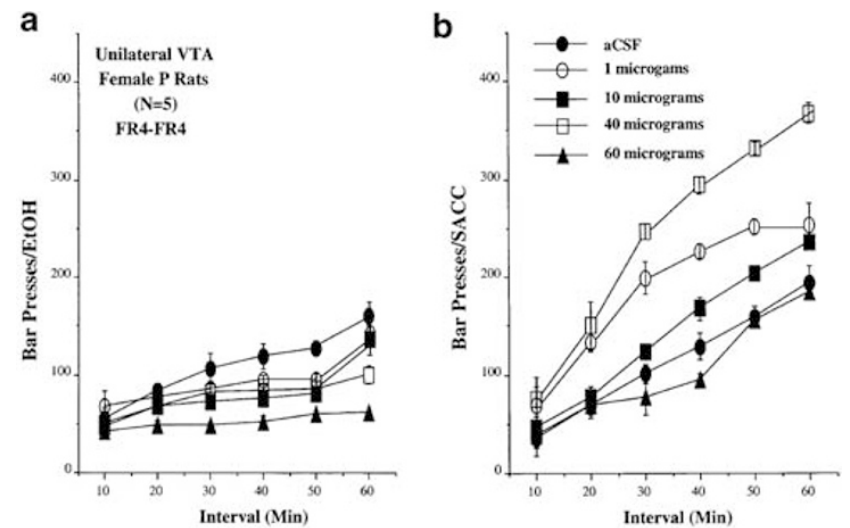

C

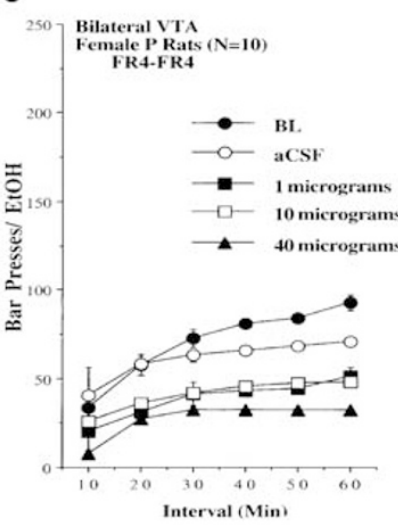

d

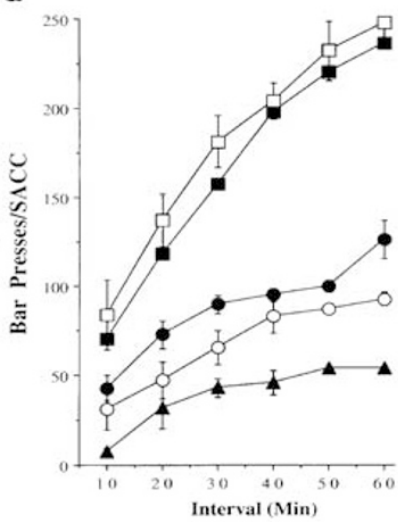

Figure 3 Cumulative time course profiles following unilateral or bilateral microinjection of nalmefene $(1-60 \mu \mathrm{g})$ in the VTA across the $60 \mathrm{~min}$ interval for $\mathrm{EtOH}-(\mathrm{a}, \mathrm{c})$ and saccharin-maintained responding $(b, d)$ relative to the aCSF condition. The data are redrawn from Figures $\mathrm{lb}$ and $\mathrm{d}$. Nalmefene was without effects during the intial 10 min interval on $\mathrm{EtOH}$ responding following the unilateral infusions; however, all doses suppressed EtOH responding by the 30 min interval $(P<0.05)$ (a), see Results section. Unilateral nalmefene in the VTA failed to alter saccharin-maintained responding at the initial 10 min interval $(p>0.05)(b)$. However, the 1.0 and $40 \mu \mathrm{g}$ doses elevated saccharin-maintained responding from the 20 to $60 \mathrm{~min}$ intervals, while the $10 \mu \mathrm{g}$ dose also elevated saccharin-maintained responding at the 40 and 50 min intervals $(p<0.05)(b)$. Unlike the bilateral infusions in the NACC (Figure 2c), only the $40 \mu \mathrm{g}$ dose suppressed EtOHmaintained responding during the initial 10 min interval $(p<0.05)$ (c). However, beginning at the 20 min interval, and throughout the duration of the $60 \mathrm{~min}$ session, the $\mathrm{I}, 10$, and $40 \mu \mathrm{g}$ doses suppressed $\mathrm{EtOH}$ maintained responding $(p<0.05)$ (c). Bilateral nalmefene in the VTA produced mild elevations with the 1 and $10 \mu \mathrm{g}$ doses on saccharinmaintained responding at the 10 min interval $(p<0.05)(d)$, while profound elevations were seen at the $30-60$ min intervals $(p<0.01)$. In contrast, the $40 \mu \mathrm{g}$ dose suppressed saccharin-maintained responding at all intervals $(p<0.05)$, except the 20 min interval $(p>0.05)$ relative to the control conditions (d). suppression was not apparent until the $40 \mathrm{~min}$ interval $(p<0.05)$. At the 50-60 min intervals, the 10,40 , and $60 \mu \mathrm{g}$ doses continued to suppress EtOH responding $(p<0.05)$. The cumulative $6 \times 5$ analyses for saccharin were: interval $(\mathrm{F}(5,24)=23.56, \quad p<0.0001) ; \quad$ dose $\quad(\mathrm{F}(4,96)=56.78$, $p<0.0001)$; interaction $(\mathrm{F}(20,96)=16.89, p<0.0001)$. Similar to the EtOH data, nalmefene failed to alter saccharinmaintained responding at the initial $10 \mathrm{~min}$ interval $(p>0.05)$ (Figure $3 b)$. In contrast, the 1 and $40 \mu \mathrm{g}$ doses elevated saccharin-maintained responding from the 20 to $60 \mathrm{~min}$ intervals $(p<0.05)$. In addition, the $10 \mu \mathrm{g}$ dose also elevated saccharin-maintained responding at the 40 and 50 min intervals $(p<0.05)$, while the $60 \mu \mathrm{g}$ dose failed to alter responding at any time interval $(p>0.05)$.

\section{Experiment 3 (Bilateral NACC Study)}

Histology. Figure $4 \mathrm{~b}$ illustrates the histological placements for the bilateral NACC rats. Of the correctly placed rats, six rats had their cannulae in the anterior NACC (Bregma: 2.70, $2.20 \mathrm{~mm}$ ), while two rats had more medial to posterior NACC placements (Bregma: 1.70, $1.00 \mathrm{~mm}$ ). One rat, however, had a single cannula in the anterior NACC (Bregma: 2.70), while the other was located in the posterior NACC (Bregma: $1.00 \mathrm{~mm}$ ). Representative photomicrographs are depicted in Figures $5 \mathrm{a}-\mathrm{c}$ illustrating three pairs of bilateral guide cannula tracks.

Microinfusions. Figure 1c (black bar) shows rates of responding maintained by EtOH following bilateral microinjection of the $0.167-40 \mu \mathrm{g}$ doses of nalmefene into the NACC core or shell. Compared with the aCSF and no injection control conditions (eg BL (average of BL1 and BL2)), bilateral nalmefene $(0.167-40 \mu \mathrm{g})$ produced a dosedependent suppression on EtOH-maintained behavior ( $\approx 89 \%$ of control levels). (EtOH mean $=163 \pm 39$; saccharin mean $=143 \pm 31)$. The nalmefene infusions yielded a significant main effect of drug treatment $(\mathrm{F}(8,64)=12.99$, $p<0.0001)$. The Newman-Keuls post hoc test revealed that, except for the lowest dose (ie $0.167 \mu \mathrm{g}$ ), all nalmefene doses significantly suppressed EtOH-maintained responding compared with the aCSF and baseline conditions $(p \leqslant 0.05)$. Figure 1c also shows rates of responding maintained by saccharin. Compared with the aCSF and no injection control conditions bilateral nalmefene in doses of $0.1671-10 \mu \mathrm{g}$ was without effect on saccharin-maintained behaviors; however, the $40 \mu \mathrm{g}$ dose reduced responding by $59 \%$ of control levels. Unlike the effects on alcohol responding, the main effect of drug dose only approached statistical significance for saccharin responding $(\mathrm{F}(8,64)=1.89, p<0.21)$. Post hoc test confirmed that the $1-40 \mu \mathrm{g}$ produced a significant dosedependent suppression on EtOH-maintained behaviors $(p<0.05)$, however, the $0.167 \mu \mathrm{g}$ dose was not effective $(p>0.05)$ (Figure 1c). Post hoc test also confirmed that only the $40 \mu \mathrm{g}$ doses significantly suppressed saccharin-maintained responding $(p<0.05)$.

Cumulative response profile. Figures $2 \mathrm{c}$ and d illustrate the cumulative response profiles for $\mathrm{EtOH}$ and saccharin, respectively, compared with the control and nalmefene treatment conditions. The cumulative $6 \times 9$ analysis was as 
a

C
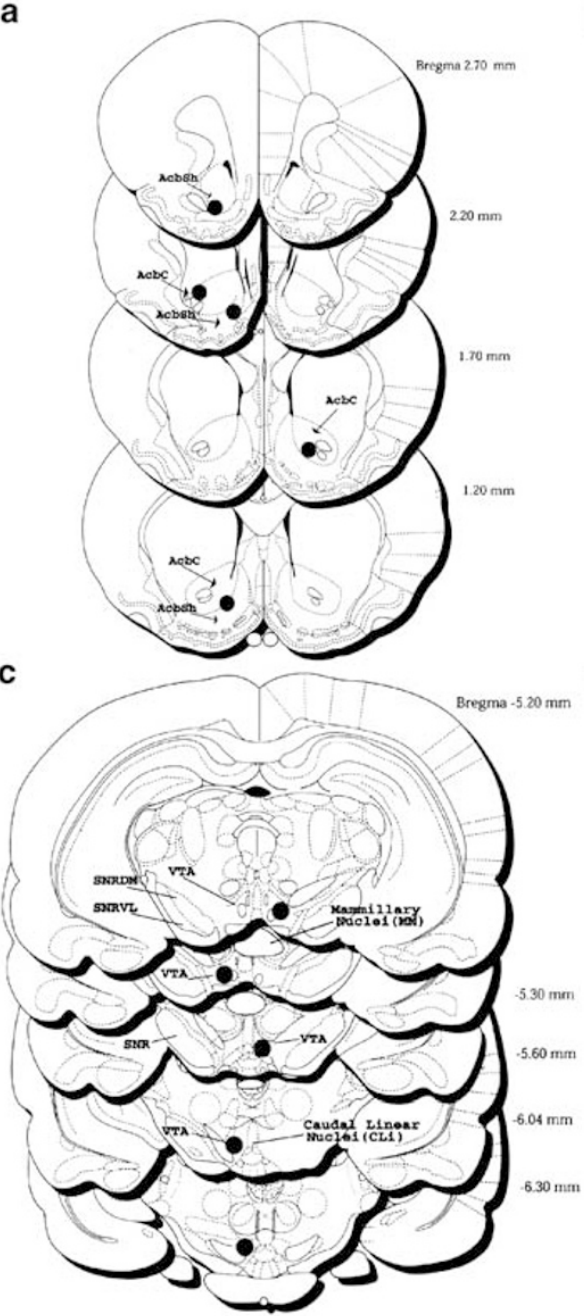

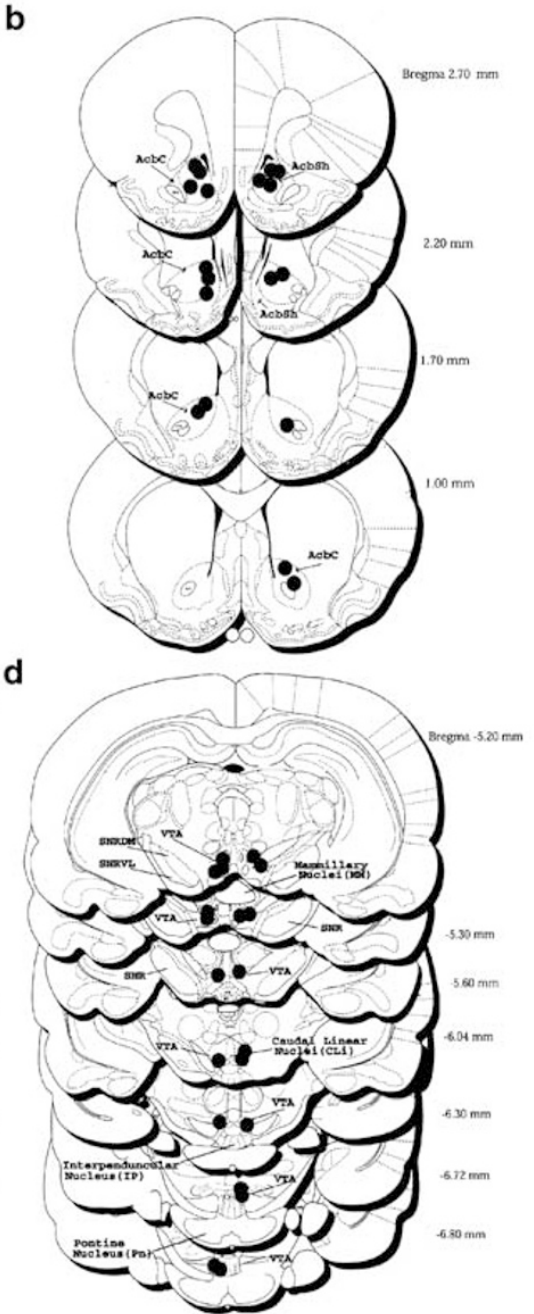

e

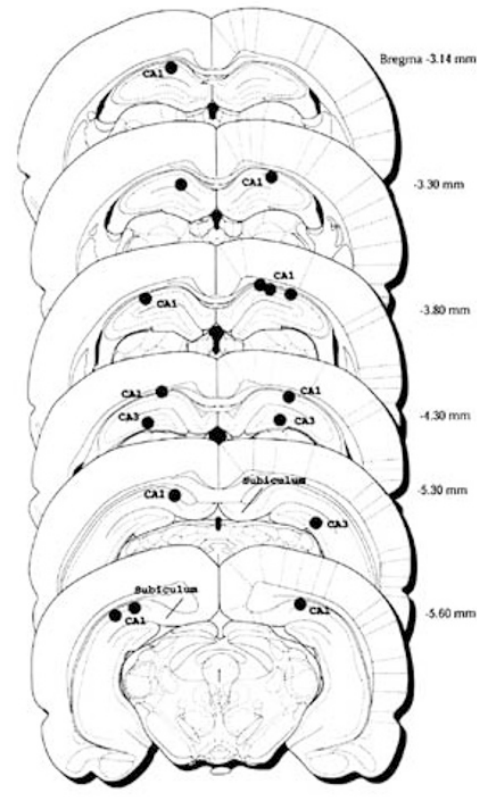

Figure 4 Reconstruction of serial coronal sections of the ' $P$ ' rat brains illustrating the unilateral $(N=5)(a)$ and bilateral $(N=9)$ (b) guide cannula tips in the NACC (shell and core). The unilateral $(N=5)(c)$ and bilateral $(N=10)(d)$ guide cannula tips in the VTA are also illustrated. Both the anterior VTA at the level of the mammillary nuclei (Bregma -4.52 to $-5.60 \mathrm{~mm}$ ) and posterior VTA at the level of the CLi/rostral interpeduncular nucleus (IPR) (Bregma -6.04 ) are shown. The hippocampus rats (eg neuroanatomical controls) are also depicted in the CAI and CA3 areas (e). Rats in the unilateral groups are represented by one solid black circle in either hemisphere. However, rats in the bilateral groups are represented by one solid black circle in the left, and one in the right hemispheres. Coronal typography sections are adapted from the rat brain atlas of Paxinos and Watson (1986). 
a
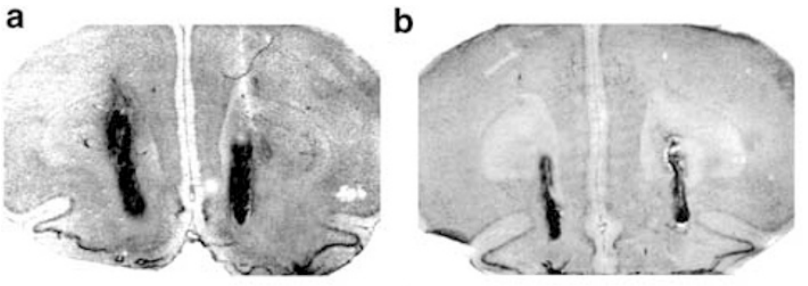

C

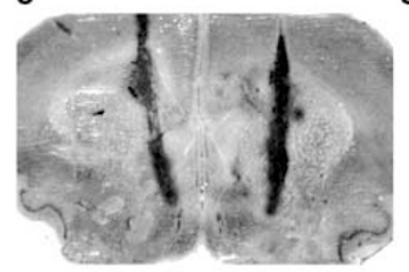

d

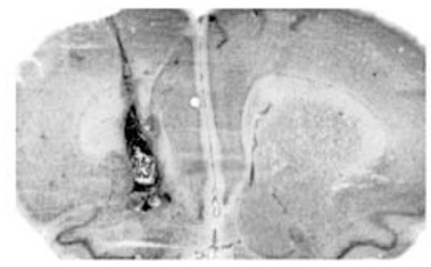

e

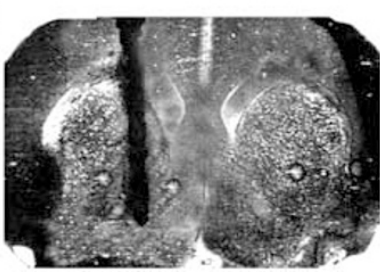

Figure 5 Representative histological photomicrographs of coronal sections for three rats with bilateral tracks $(\mathrm{a}-\mathrm{c})$ and two with a unilateral track (d, e) illustrating the anterior to medial NACC. Coronal typography was determined based on the rat brain atlas of Paxinos and Watson (1986).

follows for EtOH: interval $(\mathrm{F}(5,48)=8.06, p<0.0001)$; dose $\quad(\mathrm{F}(8,348)=64.06, \quad p<0.0001)$; $\quad$ interaction $(\mathrm{F}(40,384)=11.76, p<0.0001)$. Bilateral nalmefene infusions produced a clear dose-dependent suppression (eg $0.5-$ $40 \mu \mathrm{g}$ ) during the initial $10 \mathrm{~min}$ interval $(p \leqslant 0.05$ ) (see Figure 2c). This contrasted the effects observed with the unilateral infusions in the NACC and VTA groups (see Figures $2 a$ and $3 a$ ). Furthermore, with the exception of the $0.167 \mu \mathrm{g}$ dose at the 10 and 20 min intervals, the suppression was sustained for all doses throughout the entire $60 \mathrm{~min}$ session $(p \leqslant 0.01)$. The cumulative $6 \times 9$ analyses were as follows for saccharin: interval $(\mathrm{F}(5,48)=10.04, p<0.0001)$; dose $\quad(\mathrm{F}(8,348)=54.90, \quad p<0.0001)$; interaction $(\mathrm{F}(40,384)=19.45, p<0.0001)$. Figure $2 \mathrm{~d}$ shows that unlike the EtOH data, none of the nalmefene infusions altered responding for saccharin at the $10 \mathrm{~min}$ interval $(p>0.05)$. Moreover, the 10 and $40 \mu \mathrm{g}$ doses did not reduce saccharinmaintained responding until the $30 \mathrm{~min}$ interval $(p<0.01)$, with the $40 \mu \mathrm{g}$ dose continuing to suppress responding throughout the remainder of the $60 \mathrm{~min}$ session $(p<0.01)$. Significant suppression was seen with the lower doses (eg 5 and $1 \mu \mathrm{g}$ doses) only at the 40 and $50 \mathrm{~min}$ intervals $(p<0.05)$, albeit the suppression dissipated by the $60 \mathrm{~min}$ interval $(p>0.05)$.

\section{Experiment 4 (Bilateral VTA Study)}

Histology. Figure 4d illustrates the histological placements for the bilateral VTA rats. Examination of the histological placements revealed that of the correctly placed rats, five
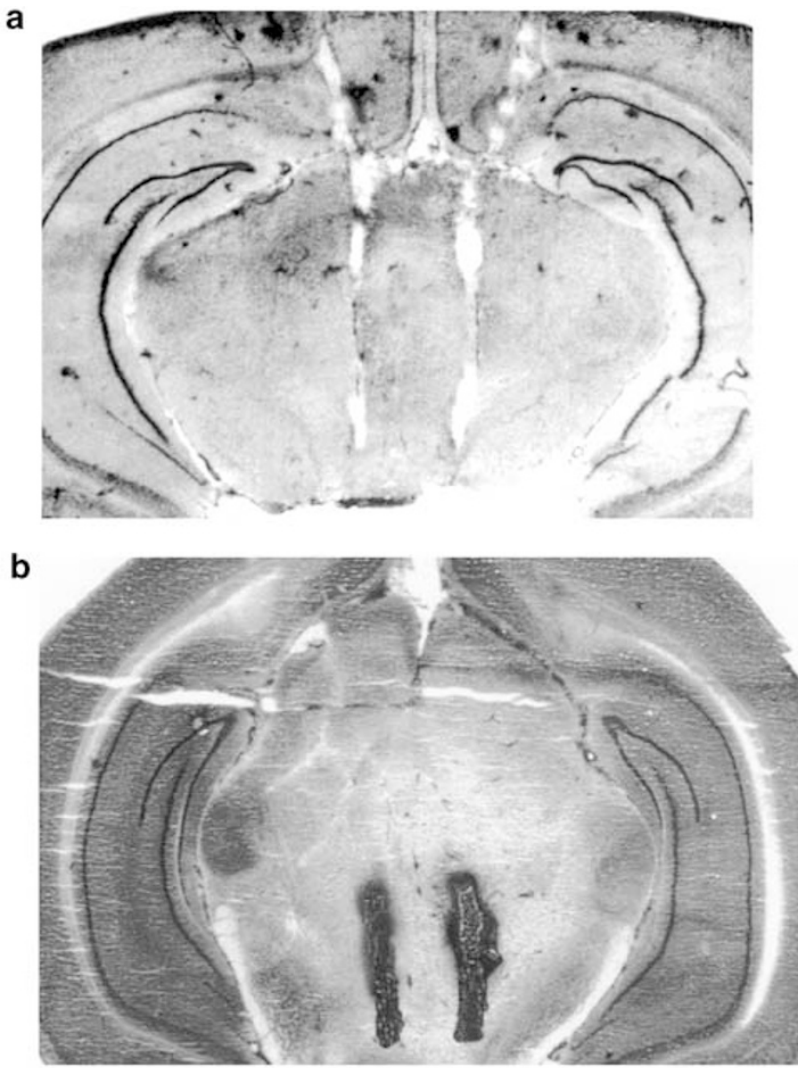

C

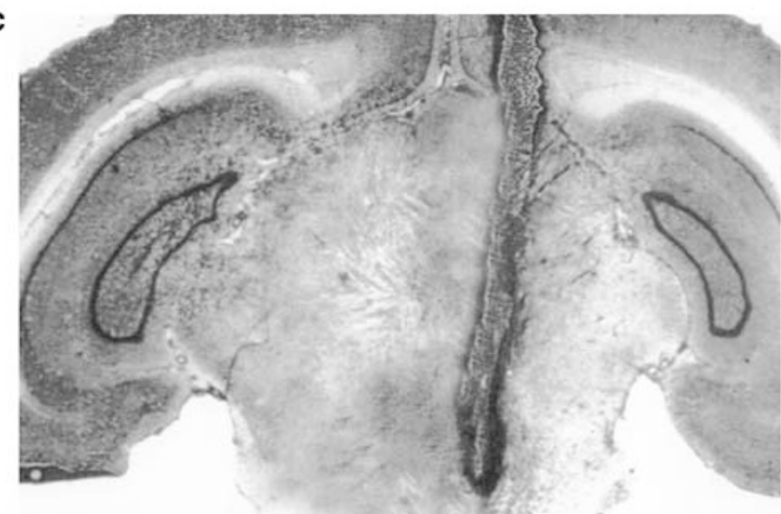

Figure 6 Representative histological photomicrographs of coronal sections for two rats with bilateral tracks in the anterior VTA ( $a, b)$, and one with a unilateral track in the posterior VTA (c). Coronal typography was determined based on the rat brain atlas of Paxinos and Watson (1986).

had both cannulae directly in the anterior VTA (Bregma $-5.20,-5.30,-5.60)$, four had both cannulae in the posterior VTA (Bregma -6.04 to -6.80 ), while one rat had a single cannula in the anterior VTA (Bregma -5.60) and the other cannula in the posterior VTA (Bregma $-6.04)$. Figures $6 a$ and $b$ depict the actual placements for ' 2 ' of the bilaterally implanted VTA rats in separate photomicrographs.

Microinfusions. Figure 1d (black bar) shows rates of responding maintained by EtOH following bilateral microinjection of the $1-40 \mu \mathrm{g}$ doses of nalmefene into the anterior 
or posterior VTA. Nalmefene produced a dose-related suppression on EtOH-maintained responding with the $1-40 \mu \mathrm{g}$ doses. Compared with the aCSF and no injection control condition (eg $\mathrm{BL})$, responding was reduced by $29-73 \%$ of control levels, resulting in a significant main effect of drug treatment $(\mathrm{F}(4,40)=5.65, p<0.0011)$. The Newman-Keuls post hoc test revealed, however, that only the 10 and $40 \mu \mathrm{g}$ doses significantly suppressed EtOHmaintained responding compared with the aCSF and baseline conditions $(p \leqslant 0.05)$. Figure $1 \mathrm{~d}$ (white bar) also shows rates of responding maintained by saccharin following bilateral microinjection of the $1-40 \mu \mathrm{g}$ doses of nalmefene. Compared with the aCSF and no injection control condition (BL), responding was reduced by 66 and $34 \%$, respectively, with the $40 \mu \mathrm{g}$ dose. In contrast, the $1 \mu \mathrm{g}$ dose markedly elevated saccharin-maintained responding by 204 and 177\%, respectively, while the $10 \mu \mathrm{g}$ dose elevated saccharin-maintained responding by 186 and 223\%, respectively (Figure 1d). These data profiles yielded a significant main effect of drug dose $(\mathrm{F}(4,40)=6.03, p<0.0007)$. Post hoc analyses confirmed that the 1 and $10 \mu \mathrm{g}$ doses significantly elevated responding maintained by saccharin $(p<0.01)$, while the $40 \mu \mathrm{g}$ dose significantly suppressed responding $(p<0.05)$.

Cumulative response profile. The cumulative $6 \times 5$ analyses were as follows for EtOH: interval $(\mathrm{F}(5,54)=7.36$, $p<0.0001)$; dose $(\mathrm{F}(4,220)=18.34, p<0.0001)$; interaction $(\mathrm{F}(20,220)=12.56, p<0.0001)$. Figure $3 \mathrm{c}$ shows that unlike the bilateral infusions in the NACC (Figure 2c), only the $40 \mu \mathrm{g}$ dose suppressed EtOH-maintained responding during the initial $10 \mathrm{~min}$ interval $(p<0.05)$. However, beginning at the $20 \mathrm{~min}$ interval, and throughout the duration of the 60 min session, the 1,10 , and $40 \mu \mathrm{g}$ doses suppressed EtOHmaintained responding $(p<0.05)$. The cumulative $6 \times 5$ analyses for saccharin were: interval $(\mathrm{F}(5,54)=13.35$, $p<0.0001)$; dose $(\mathrm{F}(4,220)=137.66, p<0.0001)$; interaction $(\mathrm{F}(20,220)=20.84, p<0.0001)$. Post hoc analyses confirmed that at the $10 \mathrm{~min}$ interval mild elevations were seen for the 1 and $10 \mu \mathrm{g}$ doses on saccharin-maintained responding $(p<0.05)$ (Figure 3d), while profound elevations were seen at the $30-60 \mathrm{~min}$ intervals $(p<0.01)$. The $40 \mu \mathrm{g}$ dose suppressed saccharin-maintained responding at all intervals $(p<0.05)$, except the $20 \mathrm{~min}$ interval $(p>0.05)$ relative to the control conditions.

\section{Experiment 5 (Bilateral CA1 and CA3 Hippocampal Study)}

Histology. Figure $4 \mathrm{e}$ shows the location of the bilateral microinjection cannulae in the CA1 and CA3 hippocampus $(N=8)$, the control locus. Examination of the histological placements revealed that five rats had both cannulae in the dorsal CA1 hippocampus, while the remaining three rats had one cannula in the dorsal CA1 hippocampus and the other in the ventral CA3 hippocampus.

Microinfusions. Figure le shows rates of responding maintained by EtOH (black bar) following bilateral microinjection of the $1-20 \mu \mathrm{g}$ doses of nalmefene into the hippocampus. Compared with the aCSF control condition, nalmefene produced a clear dose-dependent suppression on EtOH-maintained responding yielding a significant main effect of drug treatment $(\mathrm{F}(3,21)=5.06, p<0.0086)$. Responding was reduced by 41,61 , and $91 \%$ of control levels by the 1,10 , and $20 \mu \mathrm{g}$ doses, respectively. Post hoc test confirmed that all doses significantly suppressed EtOHmaintained responding compared with the aCSF condition $(p \leqslant 0.05)$. Figure $1 \mathrm{e}$ also shows rates of responding maintained by saccharin. Compared with the aCSF control condition nalmefene also dose-dependently reduced saccharin-maintained responding yielding a significant main effect of drug treatment $(\mathrm{F}(3,21)=3.04, p<0.051)$. Responding was reduced with the 1,10 , and $20 \mu \mathrm{g}$ infusions by 56,67 , and $80 \%$ of control levels, respectively. Post hoc test confirmed that the 1-20 $\mu \mathrm{g}$ doses significantly suppressed saccharin-maintained responding relative to the aCSF condition $(p \leqslant 0.05)$.

\section{DISCUSSION}

In the present study, selectively bred alcohol-preferring rats were trained to lever-press for EtOH concurrently with the availability of a palatable saccharin reinforcer. Prior to administering any drug treatment, efforts were made to match rates of responding for the two reinforcers (ie equate reward efficacy). While similar response rates for two qualitatively different reinforcers is not a guarantee of equal efficacy, when rates approximate each other at basal levels, the confound of rate may be mitigated as a factor contributing to the effect of an antagonist on EtOHmaintained responding (Samson et al, 1989; Carroll et al, 1991; Petry and Heyman, 1995; Rodefer et al, 1999; June, 2002).

\section{Intra-Accumbens and Ventral Tegmental Infusions of Nalmefene Selectively Reduce Motivated Responding for EtOH when Basal EtOH and Saccharin Response Rates are Matched}

A major finding of the present study was that when responding maintained by both $\mathrm{EtOH}$ and saccharin are matched at basal levels, microinjection of nalmefene into the NACC produced consistent dose-related and selective reductions on EtOH-maintained responding. The effects on EtOH-maintained responding were seen following unilateral as well as bilateral infusions, suggesting that only a minimal level of opioid receptor occupancy is required to observe suppression on EtOH responding within the NACC. Responding maintained by saccharin was reduced only with the highest tested dose (eg $40 \mu \mathrm{g}$ ), and when the infusions were given bilaterally. The second major finding of the present study was that selected nalmefene doses in the VTA also produced selective reductions on responding maintained by EtOH. As with the NACC infusions, responding maintained by saccharin was reduced only with the highest tested dose (eg $40 \mu \mathrm{g}$ ) and with bilateral infusions. Hence, it is likely that the suppression on saccharin responding under these conditions in both the NACC and VTA groups was due to a general suppression on consummatory behaviors. 
Differential Dose and Reinforcer 'Sensitivity' Exist in the Capacity of Intra-Accumbens and Ventral Tegmental Infusions of Nalmefene to Selectively Reduce EtOH-Motivated Behaviors

The data of the present study also provide strong support for the hypothesis that a differential sensitivity exists in the capacity of centrally administered nalmefene to reduce EtOH compared with saccharin-maintained responding in both the NACC and VTA, and that a clear separation in relation to specificity of suppression on $\mathrm{EtOH}$ responding is possible over a broad range of doses in operant studies. We previously reported a similar separation for nalmefene following parenteral administration (June et al, 1998). Similar to the present study, both the saccharin and EtOH were equated at basal levels in our previous work. In the present study, the intra-accumbens and VTA modulation by nalmefene was site specific; no selectivity in suppressing EtOH-maintained responding was observed in the CA1 and CA3 hippocampal fields, even with the lowest tested dose (eg $1 \mu \mathrm{g}$ ). Thus, opioid receptors within some (eg NACC and VTA), but not all mesolimbic substrates can selectively modulate EtOH-reinforced behaviors. Previous reports in the literature have suggested that a selectivity in reducing EtOH-motivated behaviors in rodents was difficult, equivocal, or not clearly observable (Brown and Holtzman, 1979; Herz, 1997; Schwartz-Stevens et al, 1992; Weiss and Koob, 1991; Weiss et al, 1990). However, we hypothesized that the operant contingencies under which one evaluates opiate receptor antagonists following parenteral or direct administrations into the CNS is a very important factor in observing selective antagonism on EtOH-motivated behaviors.

Nalmefene also produced a differential dose sensitivity in suppressing EtOH-motivated responding in the NACC compared with the VTA. The MED, which suppressed EtOH-maintained responding following unilateral infusion in the NACC was $10 \mu \mathrm{g}$, while the MED in the VTA was $40 \mu \mathrm{g}$. The MED dose following bilateral infusions, in the NACC was $0.5 \mu \mathrm{g}(0.25 \mu \mathrm{g} /$ per hemisphere $)$, while the MED in the VTA was $10 \mu \mathrm{g}$. EtOH responding was reduced to 56 and $85 \%$ of control levels with doses as low as 0.5 and $1 \mu \mathrm{g}$, respectively. Thus, nalmefene produced a 20 -fold greater potency in the NACC compared with the VTA in suppressing EtOH-maintained responding following bilateral infusions. The greater sensitivity of nalmefene in the NACC is likely due to the greater number of $\mu$-, and possibly $\delta$-opioid receptors in the NACC compared with the VTA (Mansour et al, 1987, 1995; McBride et al, 1998a, b; Temple and Zukin, 1987).

Nalmefene's potency also appeared to diminish substantially given unilaterally in both brain loci. These findings suggest that while unilateral injections of nalmefene with moderate-to-high doses is sufficient to produce suppression of EtOH-maintained responding, maximal receptor occupancy is achieved with bilateral infusions. Consistent with the low density of opioid receptor hypothesis in the VTA', Ragnauth et al (1997) reported that even with doses of 20-50 $\mu \mathrm{g}$ of naltrexone the suppression on food intake following intra-VTA infusions was very small. In addition, Hyytiä and Kiianmaa (1997) reported that microinjections of the $\mu$-selective antagonist, CTOP, and the $\delta_{1}$-receptor antagonist, naltrindole failed to significantly alter EtOHmaintained responding when infused into the VTA. Both of the above findings appear consistent in part, with the present study. However, the differential effects between the Hyytiä and Kiianmaa (1997) and the present study could likely be due to the rat line used, dose of the opiate antagonist given, or contingencies of the operant session. Specifically, the highest bilaterally injected dose in their study was $0.5 \mu \mathrm{g}$ and the infusions were performed in Wistar rats, whose basal response rate was substantially lower than the $\mathrm{P}$ rats. The highest bilaterally injected dose in the present study with the $\mathrm{P}$ rats was $40 \mu \mathrm{g}$. In addition, only $\mathrm{EtOH}$ was presented to the Wistar rats, while we equated both EtOH and a saccharin reinforcer in the current study.

\section{Opioid Receptors in the NACC Play a More Salient Role than VTA Receptors in Modulating the Onset of EtOH- Motivated Responding}

Previously, Heyser et al (1999) reported that local injections of methylnaloxonium into the NACC and amygdala blocked EtOH self-administration in Wistar rats during a $30 \mathrm{~min}$ operant session. When cumulative time course analyses were conducted, they reported that the suppression was not on the early phase (ie $0-10 \mathrm{~min}$ ) of the operant session, but rather occurred during the middle $(10-15 \mathrm{~min})$ of the $30 \mathrm{~min}$ session. One interpretation of these data is that opioid antagonist reduced EtOH-motivated behaviors via suppressing the maintenance, but not the onset of EtOH-reward related behaviors. In the present study, we conducted a detailed cumulative time course analyses across the $60 \mathrm{~min}$ operant session following both unilateral and bilateral infusions. In general, our results can be summarized as follows: (1) bilateral infusion of both low and high nalmefene doses (eg $0.5-40 \mu \mathrm{g}$ ) in the NACC reliably suppresses EtOH-motivated behaviors during the 'onset' (ie initial 10 min interval) of the operant session; (2) unilateral infusion of nalmefene doses in all brain loci fails to suppress the 'onset' of EtOH-motivated behaviors during the initial $10 \mathrm{~min}$ interval, however, by the end of the $20 \mathrm{~min}$ interval the suppression is reliably observed following both unilateral and bilateral infusions in the NACC and VTA; (3) bilateral infusion of the highest nalmefene doses (eg $40 \mu \mathrm{g}$ ) in the VTA, but not the NACC reliably suppresses the 'onset' of saccharin-motivated behaviors; however, unilateral infusions do not alter the onset of saccharin responding. Thus, taken together, these data suggest the onset of alcohol drinking seem to be under the control of a number of variables (dose, brain loci, contingencies of the operant session, and the type of infusion (ie unilateral $v s$ bilateral)). Nevertheless, under the conditions of the present study, our data strongly suggest that opioid receptors within the NACC appear to play a much greater role than those in the VTA in the onset of EtOH responding. In addition, opioid receptors within the NACC also appear to play a greater role in the onset of EtOH compared with saccharin responding. 
Positive/Functional Association Between $\mu$-Opioid Receptors in the NACC, but not VTA and Hippocampus and Alcohol Preference; Relation to Previous Research

Employing quantitative autoradiographic methods, McBride et al (1998a) reported higher densities of $\mu$-opioid receptors in the the NACC shell and core in P relative to NP rats, however, no differences were seen in the lines between $\delta$-receptor binding within the NACC (McBride et al, 1998b). In contrast to the NACC, substantially lower levels of $\mu$ receptor binding have been observed in the VTA of both $\mathrm{P}$ and NP rats, albeit no line differences have been observed (McBride et al, 1998a). A similar differentiation of $\mu$-opioid receptors in the NACC and VTA have also been observed in outbred rats (Mansour et al, 1987, 1995). It should be noted that the differences observed in the P and NP rats in the McBride et al (1998a) study are consistent with the higher densities of $\mu$-opioid receptors observed in the NACC of the AA compared with the ANA rat (DeWaele et al, 1994). It is possible that these innate differences in binding to $\mu$-opioid receptors may contribute to the disparate alcohol drinking in the P and AA rats. It has been suggested that the higher densities could reflect a greater number of $\mu$-opioid receptors, which could result in 'a greater responsiveness and sensitivity of the $\mu$-opioid receptor system to alcohol' (McBride et al, 1998a).

The failure of nalmefene to differentially alter $\mathrm{EtOH}$ - and saccharin-maintained responding in the hippocampus is noteworthy, particularly in light of the fact that compared with NP rats, $P$ rats have a lower, not higher distribution of $\mu$-receptor binding within the hippocampal fields (McBride et al, 1998a). Thus, a low, not high alcohol preference appears to be associated with enhanced $\mu$-opioid receptor binding in the hippocampus. Recent work from our laboratory, however, has revealed that the $\alpha_{5}$ containing $\mathrm{GABA}_{\mathrm{A}}$ receptors in the CA1 and CA3 hippocampal fields selectively regulate $\mathrm{EtOH}$, but, not saccharin-maintained responding (June et al, 2001). To our knowledge, only GABAergic mechanisms within the hippocampus have been shown to play such a specific role in modulating alcohol reinforcement. Nevertheless, given the failure of opioid receptors to selectively regulate $\mathrm{EtOH}$-motivated behaviors within the hippocampus in the present study, combined with the negative association of EtOH preference with enhanced $\mu$-opioid receptor binding (McBride et al, 1998a), we conclude that opioid receptors within the CA1 and CA3 hippocampal fields do not play a salient/specific role in regulating EtOH-motivated behaviors.

That nalmefene binds to all three major opioid receptor types $(\mu, \delta$, and $\kappa)$ undoubtedly contributes to its potency in decreasing EtOH-maintained responding (Hubbell and Reid, 1990). However, nalmefene has been shown to preferentially bind to $\mu, \kappa$, and $\delta$ receptors, respectively (Michel et al, 1985). Thus, nalmefene's potency in reducing alcohol self-administration is likely due to occupancy/ activation of central $\mu$-, rather than $\kappa$ - and $\delta$-opioid receptor subtypes. In addition, it is important to note that in vivo studies have shown low doses of nonselective opioid antagonists (eg naloxone, naltrexone) have been suggested to bind primarily to $\mu$ receptors (Chang and Cuatrecasas, 1981; Paterson et al, 1984) while higher doses $(>1.0 \mathrm{mg} / \mathrm{kg})$ result in the occupation of $\delta$ and $\kappa$ receptors (Chang and
Cuatrecasas, 1981; Leander, 1983; Leander et al, 1982). Thus, while nalmefene is a 'nonselective' opioid antagonist its selectivity ratio for the $\mu$ receptor markedly increases when lower doses are employed. Hence, the attenuation of $\mathrm{EtOH}$ self-administration in the present study particularly at the lower end of the dose response $(0.5-10 \mu \mathrm{g})$ may be due, primarily to an action of nalmefene at $\mu$-opioid receptors. Similar conclusions have been reached by other investigators employing parenteral administration of nonselective opiate antagonists with humans, primates, and rodents (June et al, 1998, 1999; Mason et al, 1994; Rodefer et al, 1999).

\section{Selectivity on Ingestive Behaviors: The Role of Brain Loci and Receptor Suybtype; Relation to Current Research on Selective and Nonselective Opioid Antagonists}

While the results of the present study suggest that microinjection of nalmefene in the NACC and VTA may preferentially attenuate the reinforcing properties of $\mathrm{EtOH}$ when more than one reinforcer is presented concurrently, it is important to note that selective and nonselective opioid receptor antagonists differentially reduce various forms of caloric and noncaloric food intake following central administration (Beczkowska et al, 1993; Bodnar, 1996; Bodnar et al, 1995; Gosnell et al, 1986; Kelley et al, 1996; Ragnauth et al, 1997). However, because the saccharin solution in the present study was devoid of calories, the degree to which nalmefene preferentially attenuates motivated responding for caloric solutions when given concurrently with EtOH is not clear. Moreover, use of the concurrent operant schedule in the present study make direct comparison across studies difficult. One hypothesis that could explain the transient increases in saccharin responding may be related to a compensatory elevation in the alternative reinforcer as a result of the reduction on responding for alcohol (see June, 2002). In fact, it has been suggested that such 'compensatory increases' are further evidence of the selectivity of a particular antagonist (see June, 2002). However, it should be noted that 'compensatory increases' in the alternative reinforcer were not observed in the NACC groups. These findings suggest that 'compensatory increases' in saccharin, or other palatable reinforcers may be more likely to occur in the VTA compared with the NACC. Moreover, the VTA may be a more viable substrate in regulating both saccharin and $\mathrm{EtOH}$ responding, while the NACC plays a greater role in regulating EtOH-motivated behaviors.

Bodnar and colleagues (Bodnar, 1996; Ragnauth et al, 1997) have evaluated the effects of nonselective and selective opioid receptor antagonists following i.c.v. and direct intracerebral injections on a variety of ingestive behaviors including palatability induced feeding (ie sucrose, saccharin). These data suggest that given i.c.v., $\mu$ antagonists are effective in reducing saccharin and sucrose intake, $\delta 1$ receptors appear more salient in regulating saccharin reinforcement, while $\kappa$-opioid receptors may be more important in mediating sucrose reinforcement. Others have reported that bilateral infusion of naltrexone and a $\mu$ selective antagonist directly in the NACC reduce sucrose intake; however, $\delta$ and $\kappa$ antagonists were ineffective 
(Bodnar et al, 1995; Kelley et al, 1996). Thus, naltrexone appears to suppress sucrose intake primarily due to blockade of $\mu$-opioid receptors.

Ragnauth et al (1997) extended this research by evaluating the effects of bilateral infusion of naltrexone, $\mu-, \delta 1$-, $\delta 2-$, and $\kappa 1$-subtype antagonists in the VTA on sucroseinduced feeding. Their data showed that only naltrexone $(20-50 \mu \mathrm{g})$ and the $\delta 2$ antagonist were effective in reducing sucrose-induced feeding (albeit the maximum reduction was only $25-39 \%$ ). These studies suggest that the VTA plays a 'relatively minor role' in sucrose-induced feeding, and that naltrexone may reduce sucrose intake primarily due to blockade of a variety of opioid receptor subtypes.

Finally, evidence is accumulating suggesting that an interaction exists between opioid peptides and dopamine in $\mathrm{EtOH}$ self-administration (Benjamin et al, 1993; Devine et al, 1993; Gonzales and Weiss, 1998; Herz, 1997). To date, the most compelling evidence to support the hypothesis is the previous work by Gonzales and Weiss (1998). Their results suggested that suppression of $\mathrm{EtOH}$ intake by opioid antagonists is a result of interference with 'dopaminedependent aspects of EtOH reinforcement' within the NACC. While these preliminary results are intriguing, additional studies are warranted wherein opiate antagonists are administered centrally.

\section{CONCLUSION}

In conclusion, the present study provides evidence that nalmefene suppresses EtOH-motivated behaviors via blockade of opioid receptors within the NACC and VTA, and under various dose conditions both reinforcer and neuroanatomical specificity can be observed. The present study also provides strong data to support the hypothesis that when saccharin is used as the alternative reinforcer and rates of responding are similar to those of EtOH, EtOH is clearly more sensitive to the antagonizing effects of nalmefene following microinfusion into the NACC and VTA. That the suppression on EtOH-maintained responding occurred reliably even with unilateral injections provide further support for the hypothesis that a minimal level of opioid receptor activation is required to suppress EtOH responding, particularly within the NACC. It has also been suggested that the effectiveness of opioid antagonists is a function of palatability or preference for $\mathrm{EtOH}$; thus, naltrexone may be more effective in attenuating consumption in rats with a greater preference for EtOH (Yeomans and Wright, 1991). This hypothesis, however, is mitigated by the similar response rates of the two reinforcers at basal levels. Finally, the cumulative time course profiles reveal that only bilateral nalmefene infusions in the NACC reliably suppresses EtOH-motivated behaviors during the initial phase (ie $10 \mathrm{~min}$ ) of the operant session. Thus, the NACC may be a more pivotal substrate in regulating the onset of EtOH-motivated responding compared with its' maintenance.

\section{ACKNOWLEDGEMENTS}

We thank IVAX Pharmaceuticals (Miami, FL) for their generous donations of nalmefene. We also extend gratitude to Drs Li (currently director of National Institute of Alcohol Abuse and Alcoholism (NIAAA)) and Lumeng and the Alcohol Research Center (Indiana University School of Medicine) for supplying the $\mathrm{P}$ rats. This research was supported in part by Grants R29AA10406, R01AA11555 (HLJ) from the NIAAA. Rancia Cummings was supported in part by the Minority Scholars Program of the School of Science at IUPUI. Shannan McCane and Collette Gray were supported in part by a mentorship grant from the Faculty Development Office at IUPUI. Katrina L Foster and Marin Garcia were supported in part by grant T35M from the National Heart, Lung, and Blood Institute of NIH (ShortTerm Training Program for Minority Students in Biomedical Research). Katrina Foster was also supported in part by a Minority Neuroscience Fellowship from the American Psychological Association. Pete McKay was supported in part by a UROP stipend from the School of Science at IUPUI. Finally, Stephanie Hawkins was supported by the IUPUI SEED Program sponsored by the American Chemical Society.

\section{REFERENCES}

Beczkowska IW, Koch JE, Bostock ME, Leibowitz SF, Bodnar RJ (1993). Central opioid receptor subtype antagonists differentially reduce intake of saccharin and maltose dextrin solutions in rats. Brain Res 621: 261-270.

Benjamin D, Grant ER, Pohorecky LA (1993). Naltrexone reverses ethanol-induced dopamine release in the nucleus accumbens in awake, freely moving rats. Brain Res 621: 137-140.

Bodnar RJ (1996). Opioid receptor subtype antagonists and ingestion. In: Cooper SJ, Clifton PJ (eds). Drug Receptor Subtypes and Ingestive Behaviour. Academic Press: London. pp 127-146.

Bodnar RJ, Glass MJ, Ragnauth A, Cooper ML (1995). General $\mu$ and $\kappa$ opioid antagonists in the nucleus accumbens alter food intake under deprivation, glucoprivic and palatable conditions. Brain Res 700: 205-212.

Brown DR, Holtzman SG (1979). Suupression of deprivationinduced food and water intake in rats and mice by naloxone. Pharmacol Biochem Behav 11: 567-573.

Carroll ME, Carmona G, May SA (1991). Modifying drug-reinforced behavior by altering the economic conditions of the drug and a non-drug reinforcer. J Exp Anal Behav 18: 361-376.

Chang KJ, Cuatrecasas P (1981). Heterogeneity and properties of opioid receptors. Fed Proc 40: 2729-2734.

Cummings R, Garcia M, Mason D, McKay PF, Foster KL, June HL (1999). Differential effects of unilateral versus bilateral microinjections of nalmefene in the nucleus accumbens and ventral tegmental area in alcohol preferring (P) rats. Alcoholism: Clin Exp Res 22: 16A [Abstract \# 62].

Devine DP, Leone P, Wise RA (1993). Mesolimbic dopamine neurotransmission is increased by administration of $\mu$-opioid recpetor antagonists. Eur J Pharmacol 243: 55-64.

DeWaele JP, Kiianmaa K, Gianoulakis C (1994). Spontaneous and ethanol-stimulated in vitro release of beta-endorphin by the hypothalamus of AA and ANA rats. Alcoholism: Clin Exp Res 18: 1468-1473.

Froehlich JC, Li TK (1993). Opioid peptides. In: Galanter M (ed). Recent Developments in Alcoholism, Vol. 11: Ten Years of Progress. Plenum Press: New York. pp 187-205.

Gonzales RA, Weiss F (1998). Suppression of ethanol-reinforced behavior by naltrexone is associated with attenuation of the ethanol-induced increase in dialysate dopamine levels in the nucleus accumbens. J Neurosci 18: 10663-10671. 
Gosnell BA, Morley JE, Levine AS (1986). Opioid-induced feeding: localization of sensitive brain sites. 277: 119-127.

Herz A (1997). Endogenous opioid systems and alcohol addiction. Psychopharmacology 129: 99-111.

Heyman GM, Oldfather CM (1992). Inelastic preference for ethanol in rats: an analysis of ethanol's reinforcing effects. Psychol Sci 3: 122-130.

Heyser CJ, Roberts AJ, Schulties G, Koob GF (1999). Central administration of an opiate antagonist decreases oral ethanol self-administration in rats. Alcoholism: Clin Exp Res 23: 1468-1476.

Hubbell CL, Reid LD (1990). Opioids modulate rat's intake of alcoholic beverages. In: Reid LD (ed). Opioids, Bulimia and Alcohol Abuse and Alcoholism. Springer-Verlag: New York. pp 145-191.

Hyytiä P, Kiianmaa K (1997). Intracerebral mu and delta opioid receptor antagonist decrease operant responding for alcohol in rats. Alcohol Alcoholism 32: 102 [Abstract].

Ikemoto S, Kohl RR, McBride WJ (1997). GABA A receptor blockade in the anterior ventral tegmental area increases extracellular levels of dopamine in the nucleus accumbens of rats. J Neurochem 69: 137-143.

Johnson BA, Ait-Daoud N (2000). Neuropharmacological treatments for alcoholism: scientific basis and clinical findings. Psychopharmacology 149: 327-344.

June HL (2002). Alcohol initiation procedures in rats: methods used in evaluating potential pharmacotherapeutic agents. In: Crawley J, Gerfen C, McKay R, Rogawski M, Sibley D, Skolnick P (eds). Current Protocols in Neuroscience Vol. 9 John Wiley and Sons: New York. pp 1-23.

June HL, Grey C, Warren-Reese C, Lawrence A, Thomas A, Cummings $\mathrm{R}$ et al (1998). The opioid receptor antagonist nalmefene reduces responding maintained by alcohol presentation: preclinical studies in alcohol preferring $(\mathrm{P})$ and outbred Wistar rats. Alcoholism: Clin Exp Res 22: 2174-2185.

June HL, Harvey SC, Foster KL, McKay PF, Cummings R, Garcia M et al (2001). GABA $\mathrm{A}_{\mathrm{A}}$-receptors containing $\alpha_{5}$ subunits in the CA1 and CA3 hippocampal fields regulate ethanol-motivated behaviors: an extended ethanol reward circuitry. J Neurosci 21: 21662177.

June HL, McCane SR, Zink RW, Portoghese PS, Li T-K, Froehlich JC (1999). The $\delta$-opioid receptor antagonist naltriben reduces motivated responding for ethanol. Psychopharmacology 147: 81-89.

Kelley AE, Bless EP, Swanson CJ (1996). Investigation of the effects of opiate antagonist infused into the nucleus accumbens on feeding and sucrose drinking in rats. J Pharmacol Exp Ther 278: 1499-1507.

Kelley AE, Berridge KC (2002). The neuroscience of natural rewards: relevance to addictive drugs. J Neurosci 22: 3312-3320.

Koob GF, Sanna PP, Bloom FE (1998). Neuroscience of addiction [Review]. Neuron 21: 467-476.

Kranzler HR (2000). Pharmacotherapy of alcoholism: gaps in knowledge and opportunities for research. Alcohol Alcoholism 35: 537-547.

Krishnan-Sarin S, Jing S-L, Kurtz DL, Zweifel M, Portoghese PS, Li $\mathrm{T}-\mathrm{K}$ et al (1995a). The delta opioid receptor antagonist naltrindole attenuates both alcohol and saccharin intake in rats selectively bred for alcohol preference. Psychopharmacology 120: 177-185.

Leander DJ (1983). A kappa opioid effect: increased urination in the rat. J Pharmacol Exp Ther 224: 89-94.

Leander DJ, Hart JC, Lochner MA, Hynes MD, Zimmerman DM (1982). Novel phenylpiperidine opioid antagonists and partial agonists: effects on fluid consumption. Eur J Pharmacol 81: 185-192.

Lewis MJ, June HL (1990). Neurobehavioral studies of ethanol reward and activation. Alcohol 7: 213-219.
Lumeng L, Murphy JM, McBride WJ, Li T-K (1995). Genetic influences on alcohol preference in animals. In: Beglieter $\mathrm{H}$, Kissin B (eds). Genetics of Alcoholism. Oxford University Press: New York, 165-201.

Mansour A, Fox CA, Akil H, Watson SJ (1995). Opioid-receptor mRNA expression in the rat CNS: anatomical and functional implications. Trends Neurosci 18: 22-29.

Mansour A, Khachaturian H, Lewis ME, Akil H, Watson SJ (1987). Autoradiograhpic differentiation of mu, delta, and kappa opioid receptors in the rat forebrain and midbrain. J Neurosci 7: 24452464.

Mason BJ, Ritro EC, Morgan RO, Salvato F, Zimmer E, Goldberg G et al (1994). A double-blind, placebo-controlled pilot study to evaluate the efficacy and safety of oral nalmefene HCL for alcohol dependence. Alcoholism: Clin Exp Res 18: 464.

Mason BJ, Salvato FR, Williams LD, Rivito EC, Cutler RB (1999). A double blind, placebo-controlled study of oral nalmefene for alcohol dependence. Arch Gen Psychiatry 56: 719-724.

McBride WJ, Chernet E, McKinzie DL, Lumeng L, Li T-K (1998a). Quantitative autoradiography of mu-opioid receptors in the CNS of alcohol-naïve alcohol-preferring $\mathrm{P}$ and non-preferring $\mathrm{NP}$ rats. Alcohol 16: 317-323.

McBride WJ, Learn J, Chernet E, Lumeng L, Li TK (1998b). Regional CNS densities of mu-opioid receptors in HAD and LAD rats (Abstract no. 252). Alcoholism: Clin Exp Res 22: 44A.

McBride WJ, Li T (1998). Animal models of alcoholism: neurobiology of high alcohol-drinking behavior in rodents. Crit Rev Neurobiol 12: 339-369.

McBride WJ, Murphy JM, Gatto GJ, Levy AD, Yoshimoto K, Lumeng L et al (1993). CNS mechanisms of alcohol selfadministration. Alcohol Alcoholism 2(Suppl): 463-467.

McKinzie DL, Eha R, Murphy JM, McBride WJ, Lumeng L, Li T-K (1996). Effects of taste aversion training on the acquisition of alcohol drinking in adolescent P and HAD rat lines. Alcoholism: Clin Exp Res 20: 682-687.

Michel ME, Bolger G, Weissman BA (1985). Binding of a new opiate antagonist, nalmefene, to rat brain membranes. Methods Findings Exp Clin Pharmacol 7: 175-177.

Nowak KL, McBride WJ, Lumeng L (1998). Blocking $\mathrm{GABA}_{\mathrm{A}}$ receptors in the anterior ventral tegmental area attenuates ethanol intake of the alcohol-preferring $\mathrm{P}$ rat. Psychopharmacology 139: 108-116.

O’Malley SS, Jaffe AJ, Chang G, Schottenfeld RS, Meyer RE, Rounsaville B (1992). Naltrexone and coping skills therapy for alcohol dependence. Arch Gen Psychiatry 49: 881-887.

Paterson SJ, Corbett AD, Gillan MG, Kosterlitz HW, McKnight AT, Robson LE (1984). Radioligands for probing opioid receptors. J Recept Res 4: 143-154.

Paxinos G, Watson C (1986). The Rat Brain in Stereotaxic Coordinates. Academic Press: Sydney.

Petry NM, Heyman GM (1995). Behavioral economic analysis of concurrent ethanol/sucrose and sucrose reinforcement in the rat: effects of altering variable-ratio requirements. J Exp Anal Behv 64: 331-359.

Ragnauth A, Ruegg H, Bodnar RJ (1997). Evaluation of opioid receptor subtype antagonist effects in the ventral tegmental area upon food intake under deprivation, glucoprivic and palatable conditions. Brain Res 767: 8-16.

Reid LD, Hubbell CL (1992). Opioids modulate rats' propensities to take alcoholic beverages. In: Naranjo CA, Sellers EM (eds). Novel Pharmacological Interventions for Alcoholism. SpringerVerlag: New York. pp 121-134.

Rodd-Henricks ZA, McKenzie DL, Crille RS, Murphy JM, McBride WJ (2000). Regional heterogeneity for the intracranial selfadministration of ethanol within the VTA of female Wistar rats. Psychopharmacology 149: 217-224.

Rodefer JS, Campbell UC, Cosgrove KP, Carroll ME (1999). Naltrexone pretreatment decreases the reinforcing efficacy of 
ethanol and saccharin but not PCP or food under concurrent progressive-ratio schedules in rhesus monkeys. Psychopharmacology 141: 436-446.

Samson HH, Grant KA (1985). Chlordiazepoxide effects on ethanol self-administration: dependence on concurrent conditions. J Exp Anal Behav 43: 353-364.

Samson HH, Haraguchi M, Tolliver GA, Sadeghi KG (1989). Antagonism of ethanol-reinforced behavior by the benzodiazepine inverse agonists RO15-4513 and FG 7142: relationship to sucrose reinforcement. Pharmacol Biochem Behav 33: 601-608.

Schwartz-Stevens KS, Files FJ, Samson HH (1992). Effects of morphine and naloxone on ethanol-reinforced responding in nondeprived rats. Alcoholism: Clin Exp Res 16: 822-832.

Temple A, Zukin RS (1987). Neuroanatomical patterns of $\mu, \delta, \kappa$, opioids receptors of rat brain as determined by quantitative in vitro receptor autoradiography. Proc Natl Acad Sci USA 84: 4308-4312.
Volpicelli JR, Alterman AI, Hayashida M, O’Brien CP (1992). Naltrexone and the treatment of alcohol dependence. Arch Gen Psychiatry 49: 876-880.

Volpicelli JR, Rhines KC, Rhines JS, Volpicelli LA, Alterman AI, O'Brien CP (1997). Naltrexone and alcohol dependence: the role of subject compliance. Arch Gen Psychiatry 54: 737-742.

Weiss F, Koob GF (1991). The neuropharmacology of ethanol selfadministration. In: Meyer RF, Koob GF, Lewis MJ, Paul S (eds). Neuropharmacology of Ethanol. Birkhauser: Boston. pp 125-162.

Weiss F, Mitchiner M, Bloom FE, Koob GF (1990). Free-choice responding for ethanol versus water in alcohol preferring $(\mathrm{P})$ and unselected Wistar rats is differentially modified by naloxone, bromocriptine, and methysergide. Psychopharmacology 101: 178-186.

Yeomans MR, Wright P (1991). Lower pleasantness of palatable foods in nalmefene-treated human volunteers. Appetite 16: 249-259. 